La Palabra No. 17 • ISSN 0121-8530

Julio-Diciembre 2010 • pp. 17-28

\title{
La imasen del indio en Ingermina o la hija de Calamar de Juan José Nieto: de la hija de Calamar a la hija de Velásquez ${ }^{*}$
}

\author{
Donald Freddy Calderón Noguera* \\ Universidad Pedagógica y Tecnológica de Colombia \\ donald.calderon@uptc.edu.co
}

\section{Resumen:}

Este artículo constituye un avance de investigación del proyecto Imago: construcción de la Imagen de América Latina a través de la Literatura y las Artes, el cual tiene como propósito problematizar, de manera interdisciplinaria, el papel de los textos artísticos en la construcción de la imagen que tenemos sobre nuestra región continental. Se presenta una reflexión teórica acerca de la imagen y se deletrea la novela Ingermina, recomponiendo la imagen del indio desde las refracciones que espejea el texto.

\section{Palabras clave:}

Palabras clave: imagen, indio, novela, campesino.

* Avance de investigación del proyecto Imago, llevado a cabo por la Corporación Literaria Si Mañana Despierto para la Creación e Investigación de la Literatura y las Artes (SMD).

** Licenciado en Filología y Literatura, Magíster en Lingüística Hispánica, Doctorando en Lenguaje Humano de la UNED-España. Docente de la Escuela de Idiomas de la Universidad Pedagógica y Tecnológica de Colombia (UPTC), Director de la Maestría en Lingüística de la UPTC. Líder del grupo de investigación SMD. Autor de libros y artículos sobre escritura y lenguaje. Par evaluador reconocido por Colciencias en el área de Lingüística. 


\title{
The imase of the Indian in Ingermina o la Hija de Calamar [Ingermina or Squid's daughter] by Juan José Nieto: from Squid's daughter to Velásquez's daughter
}

\begin{abstract}
:
This article constitutes a research advance of the interdisciplinary research project "Imago: the Construction of Latin American Image Repertoire through Literature and the Arts", whose purpose is to question the role of artistic texts in the image construction of our continental region. In this study, we present a theoretical reflection on image, and following a literal reading of the novel Ingermina, we reconstruct the image of "Indian" through the refractions mirrored by the text.
\end{abstract}

\section{Key words:}

image, Indian, novel, peasant. 


\section{Ingermina o la hija de Calamar}

Es pionera de la novela en Colombia. Escrita por Juan José Nieto en 1844 y publicada en Jamaica a "expensas de unos amigos del autor" (Nieto, 2001. p. 27); relato de ficción declarada: "No me ha faltado razón para distraer el fastidio causado por un encierro de más de cuatro meses, en la composición de esta otra novela" (p. 27), que narra acontecimientos relacionados con el encuentro de dos culturas, ubicados espacio-temporalmente en Cartagena de Indias y sus alrededores, sucedidos, según la voz narrativa y la declaración de la portada de la novela, entre 1533 y 1537. Nos encontramos, por lo tanto, con un texto fundante de la cultura colombiana, donde, desde la ficción narrativa, se presenta un relato híbrido en el cual la nota histórica, con sus referencias citadas al margen, y los personajes españoles e indígenas toman como punto de referencia hechos sucedidos en este lugar de nuestro país. El autor de la novela tenía conocimiento del carácter fundante de su texto, por ello nombra Ingermina a su heroína, esto es el germen, el comienzo, de una zaga de relaciones de pugna, esclavitud, opresión y sujeción en la que la cultura de Occidente, con la fuerza y la tecnología de los españoles, sale triunfante.

La trama de la novela se teje en las relaciones de dos culturas: la española, que arribó a la tierra de los Calamar en 1501, y la de los pueblos indígenas, que en el tiempo de los hechos narrados llevan 32 años de sumisión y resistencia. El pretexto narrativo se centra en el idilio amoroso sostenido entre Ingermina y Alonso de Heredia, hermano de Pedro de Heredia, conquistador español de la hoy Cartagena de Indias.

Con respecto a la novela, en el prólogo, escrito por Germán Espinoza para la edición que publica el Fondo Editorial Universidad Eafit, se afirma:

[Es] una obra cuya importancia radica en haberse realizado en una Hispanoamérica que no había conseguido fundar una tradición novelística y en un medio que parecía refractario al género. En un medio, para resumir, en el cual, literariamente, predominaba el poema heroico o épico y cierta objetividad lírica de prosapia neoclásica, ajena a complicaciones psicológicas (2001, p. 10).

El género novelesco no se había aclimatado todavía en predios de Hispanoamérica y el pronóstico de varios entendidos era que no habría de aclimatarse nunca. En tal sentido, no resulta ocioso recordar que durante la dominación española, la circulación de novelas (y en general de obras de ficción) estuvo prohibida en esta área del mundo, por el temor de que el universo de la fantasía obrase peligrosas transformaciones en las mentes habitualmente sometidas $(2001$, p. 15).

[Que anteriores a la novela] solo poseemos referencia de dos novelas escritas en territorio colombiano: la titulada Desierto Prodigioso y Prodigios del Desierto, publicada en el siglo XVII, con escasa resonancia, por Pedro de Solís y Valenzuela; y, en 1841, María Dolores, del poeta José Joaquín Ortiz (2001, p. 5).

[Que] El único antecedente de narrativa magistral existente en Colombia en el instante de escribirse Ingermina, era el Carnero de Rodríguez Freyle, escrito en el siglo XVII. Sólo que lo relatado en este variadísimo libro, o al menos eso lo afirmó su autor, no es ficción, sino crónica de hechos acaecidos en la realidad (2001, p. 15).

Idelber Avelar (2011) indica que:

La dinámica particular de las relaciones sociales en la región Caribe de Colombia permitió que se produjera allí, por primera vez en el país, un corpus novelístico de complejidad bastante notable, cuando se compara con las novelas que se empezaban a publicar en otros países latinoamericanos. Las novelas escritas por Juan José Nieto (1804-1866) en su exilio jamaiquino en la década de 1840 nos presentan personajes tridimensionales y resoluciones narrativas no obvias, que no se encontrarían con tanta frecuencia en las novelas romántico-sentimentales o costumbristas que, por aquel entonces, pasaban a dominar el canon literario latinoamericano. Que estas novelas hayan sido el producto de la pluma de Nieto, un mulato, y que hayan visto la imprenta en el exilio, no son, desde luego, datos fortuitos. La derrota del proyecto liberal representado por Nieto es un elemento constitutivo, que tendría importante papel en ese corpus narrativo que se gestaba. 
Donald Freddy Calderón Noguera

Salvo el caso del Carnero, el lector aficionado, desconoce la existencia de otras novelas decimonónicas. Esto obedece a razones políticas y culturales, tal como lo explica Raymond Williams:

El período formativo de la nueva nación, de 1810 a 1862, estuvo dominado intelectualmente por dos hombres de letras, Julio Arboleda (1817-1862) y José Eusebio Caro (1817-1853), quienes no escribieron novelas. Los escritores de esta época eran típicamente terratenientes jóvenes y aristócratas urbanos. Muchos de ellos participaron en la guerra de independencia o fueron hijos de participantes. Arboleda y Caro se distinguieron por su poesía y pertenecían a la clase acomodada. Desde el punto de vista de nuestro presente, podemos afirmar que Eugenio Díaz y Juan José Nieto fueron dos novelistas importantes, quienes durante su existencia, sin embargo, fueron vistos como intelectuales advenedizos, cuya obra literaria era de poca importancia. Se creía que sus novelas y que el género novelístico, no contribuían significativamente a la empresa ideológica, a la política de la clase alta o a la élite intelectual.

\section{Acerca de la imaginación, la imagen, el imaginario}

Cuando se habla de la imagen o se hace uso de ella, generalmente es concebida como complemento del sentido, recurso de explicación o ilustración. Esta disminución del carácter y funcionalidad de la imagen se debe al pensamiento racionalista cartesiano, que ha constituido lo percibido por los sentidos, lo mensurable, verificable empíricamente, como única forma de conocimiento.

Para esta reflexión inicial sobre la imagen, se toma como punto de partida la crítica de Gilbert Durand en relación con la función de la imagen en la sociedad moderna, la cual, según el autor, se encuentra "a mitad de camino entre la solidez de la sensación y la pureza de la idea" (2006, p. 26), es decir, está ubicada en un término medio donde es poco significativa. El desprestigio de la imagen llega incluso a desposeerla de su carácter lumínico, ilustrativo.

Por ello, el pensamiento positivo afirma que "la imagen es una sombra del objeto" o, incluso, "ni siquiera es un modelo de lo real"; la imagen no es más que un "objeto fantasma", sin "consecuencia", de todas las cualidades de la imaginación no es más que "nada": los objetos imaginarios son "equívocos"; vida ficticia, congelada, disminuida, escolástica que, para la mayoría de la gente, no es más que un mal menor, precisamente lo que un esquizofrénico desea" (Durand, 2006, p. 27). Esta concepción llega a determinar la imagen como un obstáculo que entorpece el acceso a la "idea clara y distinta" y configura la trayectoria de esta como desviación y entrenamiento ocioso que obstruye la búsqueda de la verdad por la intromisión del sujeto y lo subjetivo, impidiendo el reconocimiento racional del objeto.

La revisión de Durand en torno a la caída de la imagen en Occidente continúa explicando cómo para el positivismo y las ciencias centradas en el objeto "el imaginario no era más que una ilustración didáctica. Monismo mecanicista, metafórico o nadificante, poco importa: la imaginación, ya haya sido reducida a la percepción debilitada, al recuerdo de la memoria" (2006, p. 30). Desde esta perspectiva, entonces, la imagen es reducida a su constitución formal, descargada de su contenido semántico y percibida como simple alegoría que ejemplifica de otra manera, secundaria, lo cual se puede explicar con el concepto lógico.

El extremo de esta postura se expresa en que las "imágenes nada agregan al sentido de las nociones abstractas... lo contrario del sentido propio, el sentido figurado, no puede entonces sino ser un sentido sucio" (Durand, 2006, p. 32). Esto significa que para este generalizado grupo de pensadores lógico-positivistas sólo es posible acceder al conocimiento abstracto mediante el uso del concepto expresado en sistemas lingüísticos de notación, donde los procesos mentales se traducen en encadenamientos formales expresados en lenguas naturales o artificiales. Así, la imagen, la imaginación y el imaginario, que constituyen arquetipos, son un residuo indeseado, asunto de poetas y soñadores, que no impactan ni construyen ciencia ni sociedad.

Por fortuna, las Ciencias Sociales y Humanas, en especial con pensadores como Bachelard, Ortiz Osés, 
Geertz, Rorty (con su giro lingüístico), Heidegger (en Ser y Tiempo), Nietszche y el mismo Durand han venido redimensionando esta postura, en la cual la ausencia del sujeto y de la subjetividad ha constituido un conocimiento eminentemente práctico, utilitarista, mecanicista, inmediatista y reducido, que, entre otras cosas, sólo ha construido una sociedad donde el ser es lo que sabe, lo que hace y lo que posee. Esta postura ha figurado un sujeto altivo, autoritario, presuntuoso de poder dominar el mundo físico a través del conocimiento, aun hasta el punto de convencerse de ser un semidiós todopoderoso. Esto trae como consecuencia el desencanto, el desarraigo, la exacerbación del ser y la preeminencia de la pulsión que convierte las sensaciones en mercancía inmediata.

Bachelard, en su Poética del espacio, afirma que "para poder vivir directamente las imágenes" es preciso que la imaginación sea lo suficientemente humilde para dignarse a llenarse por completo de imágenes, porque si uno se niega a esa humildad primordial, a ese abandono originario del fenómeno, jamás -por falta de elemento inductor-podría hacerse esa "repercusión", que es el inicio mismo de la progresión fenomenológica". Lo anterior significa un cambio de perspectiva en tres dimensiones: a) regreso del sujeto y lo subjetivo, como actor y materia del conocimiento, b) destronamiento del sujeto de su obsesión de hacer, saber y tener, y c) comprensión de la imagen desde su mismo universo imaginario; esto debido a que

en el dominio de la imaginación, donde la imagen por degradada que se la pueda concebir - en sí misma es portadora de un sentido que no debe ser buscado fuera de la significación imaginaria. Finalmente, lo único significativo es el sentido figurado, ya que el supuesto sentido propio no es más que un caso particular y mezquino de la vasta corriente semántica que deseca las etimologías (Durand, 2006, p. 33).

De acuerdo con Bachelard,

la imaginación es un dinamismo organizador y este un factor de homogeneidad en la representación.... La imaginación es potencia dinámica que "deforma" las copias pragmáticas suministradas por la percepción, y ese dinamismo reformado de las sensaciones se convierte en el fundamento de toda la vida psíquica porque "las leyes de la representación son homogéneas" ; ya que la representación es metafórica en todos sus niveles, y puesto que todo es metafórico, "en el nivel de la representación todas las metáforas se igualan" (Durand, 2006, p. 34).

Esta tesis es fundamental, pues plantea la posibilidad de relacionar de manera intersubjetiva las representaciones, en este caso registradas en el texto literario, donde la realidad y la subjetividad del autor se conjugan e intersectan en el imaginario.

En síntesis, la imaginación "la mayor parte de las veces aparece en su propio impulso como resultante de un acuerdo entre los deseos y los objetos del ambiente social y natural" (Durand, 2006, p. 42). La imaginación, por lo tanto, no es ajena al ambiente social ni al universo de los objetos, surge de una relación entrópica, paradigmática, semántica, metafórica en la cual los deseos del sujeto, sus intereses motivacionales y los artefactos culturales se relacionan para soportar una manera especial de ser en el mundo y transformarlo; transformación que libera al sujeto, lo delinea como actor social, quien a la vez es agente emancipador. De esta forma, "la imaginación... es origen de una liberación. Las imágenes no valen por las raíces libidinosas que ocultan, sino por las flores poéticas y míticas que revelan" (Durand, 2006, p. 42), demostrando el carácter totalizante de las imágenes constituidas no sólo por la dominante erótica, sino también, por la postural y digestiva, expresadas en regímenes diurnos y nocturnos.

Esta deriva de pensamiento permite establecer postulados teóricos que inciden en las maneras de acceder a la imagen y sus imaginarios, así:

- La imagen y los símbolos que representa se producen, reproducen y evolucionan en el imaginario, en el universo semántico, es decir, ideacional.

- El estudio de los imaginarios tiene como propósito la comprensión de arquetipos antropológicos, imágenes generales, "esquemas o potencialidades funcionales", que "moldean inconscientemente el pensamiento" (Durand, 2006, p. 33). 
- Comprender el imaginario es vislumbrar el "sentido" de las metáforas, ese gran semantismo del imaginario, la matriz original a partir de la cual se despliega todo pensamiento racionalizado y su cotejo semiológico.

- Los símbolos se heredan fenotípicamente mediante procesos sociales: "todo pensamiento simbólico es, en primer lugar, símbolo de conciencia de grandes símbolos hereditarios" (Durand, 2006, p. 42).

- Los imaginarios se expresan en un devenir, en camino que Jung denomina trayecto antropológico, entendido como "el incesante intercambio que existe en el nivel de lo imaginario, entre las pulsiones subjetivas y asimiladoras y las intimaciones objetivas que emanan del medio cósmico y social" (Durand, 2006, p. 43); esto significa que lo real y la realidad son interacciones entre el sujeto, lo físico y su comprensión social.

- Para acceder al imaginario se requiere de un método convergente, pragmático y relativista que busque "localizar vastas constelaciones de imágenes, constelaciones más o menos constantes y que aparecen estructuradas por cierto isomorfismo de los símbolos convergentes" (Durand, 2006, p. 45), entendiendo el isomorfismo como el cúmulo de imágenes que se reiteran de manera intersubjetiva.

- Los símbolos circulan en una constelación, porque son desarrollos de un mismo tema arquetípico y de variaciones sobre un arquetipo" (Durand, 2006, p. 46).

- Para ingresar al imaginario se propone como objeto de análisis el esquema, "es una generalización dinámica y afectiva de la imagen constituye la facticidad y la no sustantividad general del imaginario.... Son precisamente estos esquemas los que forman el esqueleto dinámico, el boceto funcional de la imaginación" (Durand, 2006, p. 62).

- La identificación de los esquemas, entendidos como "trayectos encarnados en representaciones concretas y determinadas" (Durand, 2006, p. 62). En esta investigación el esquema es el relato novelado por analizar.

- Los arquetipos funcionan en regímenes diurnos y nocturnos que dialogan, cohabitan, confluyen o chocan, aíslan, contradicen; relativizando y fragmentado al sujeto, haciéndolo frágil y obligándolo a negociar su existencia en el conglomerado social.

El régimen diurno concierne a la dominante postural, la tecnología de las armas, la sociología del soberano mago y guerrero, los rituales de la elevación y la purificación. El régimen nocturno se subdivide en dominantes digestiva y cíclica; la primera subsume las técnicas del continente y el hábitat, los valores alimenticios y digestivos, la sociología matriarcal y nutricia, y la segunda agrupa las técnicas del ciclo, del calendario agrícola y de la industria textil, los símbolos naturales o artificiales del retorno, los mitos y los dramas astrobiológicos (Durand, 2006, p. 60).

En definitiva, "Ios arquetipos constituyen el punto de unión entre el imaginario y los procesos racionales" (p. 63).

Una vez puntualizadas estas generalidades teóricas, se procede a leer la imagen en el texto, para lo cual se procede así:

- Deletreo del texto: lectura de los componentes de la imagen construida verbalmente.

- Caracterización de las representaciones que sostienen el imaginario.

- Explicación de los arquetipos.

\section{El deletreo}

Este avance presenta el deletreo del texto, quedando para el resultado final la caracterización de las representaciones y la explicación de los arquetipos.

El texto está compuesto por cuatro partes: Obsequio a la señora Teresa Cuervo de Nieto; Breve noticia histórica de los usos, costumbres y religión de los habitantes del pueblo Calamar. Tomada de Ios fragmentos de una antigua crónica inédita de agustinos de Cartagena, por Fray Alonzo de la Cruz y Paredes; Parte uno y Parte dos. Éstas cumplen funciones narrativas y permiten caracterizar la imagen del indio. 


\section{Obsequio a la señora Teresa Cavero de Nieto}

Esta dedicatoria esboza rasgos propios de la voz del autor implícito, quien habiendo sido condenado al destierro y a prisión por la causa santanderista, en actitud romántica, ocupa su tiempo escribiendo una novela, en la cual, trescientos años después, recrea cómo se difumina la imagen del indio calamarí.

La dedicatoria cumple, además, la función discursiva de constituir al lector implícito, al instaurar una función pragmática declarada por el mismo autor:

$Y$ como mis intenciones en esta parte no pueden ser satisfechas con toda la munificencia de mis deseos, no tengo otra cosa con qué obsequiarte que con mi Ingermina que es un modelo de tus virtudes, y que como hecha para ti, tú serás la única que verás con indulgencia sus efectos (Nieto, 2001, p. 28).

Lo focal de la afirmación está en el reflejo entre Ingermina y la señora Cavero, de tal manera que la primera se configura con rasgos de la segunda. También nos señala el carácter íntimo del lector, estableciendo un espacio de confidencialidad con el propósito de darle veracidad al relato.

Breve noticia histórica de los usos, costumbres y religión de los habitantes del pueblo Calamar. Tomada de los fragmentos de una antigua crónica inédita de agustinos de Cartagena, por Fray Alonzo de la Cruz y Paredes

Esta parte es fundamental, ya que permite comprender el contexto cultural de uno de los grupos sociales que rivalizan y se relacionan en el texto. La enunciación de este apartado es totalmente descriptiva y su estructura corresponde a los relatos de viaje escritos durante la Conquista y la Colonia con propósitos científicos.

Las afirmaciones narradas presentan a los indios de Calamar como un honorable adversario y posterior aliado: "Entre todas las parcialidades de Indios que había en sus inmediaciones, la de Calamar era la más numerosa, la más fuerte y la más civilizada" (Nieto,
2001, p. 29). "Eran inquietos, valientes y de genio indomable" (p. 29)

Los Calamareños eran de buena estatura y bien formados. Eran fuertes, sagaces y determinados. Aunque no dejaban de participar de la mala fe que ha distinguido generalmente a los Indígenas. Sobresalían en agilidad e inteligencia a sus vecinos, particularmente en la pesca y cacería. Sus mujeres y las de Turbaco eren tenidas por las más hermosas de la comarca (p. 42).

No es desconocido que para exaltar la valentía del conquistador, se exaltaba la de su rival.

La crónica antigua expone una imagen del indio que ha sido interpretada desde la perspectiva del español, mediante focalizaciones contrastivas donde las prácticas culturales de los calamareños son validadas o refutadas de acuerdo con la óptica del invasor, en la medida que se parezcan o no. Este carácter se muestra así:

Los calamareños poseen un conocimiento fraccionado e incompleto

Este pueblo adoraba al Sol, pero prestaba un culto especial a la Luna, porque conocía alguna parte de la influencia de este astro sobre la naturaleza.... Por una costumbre rara, y benéfica a la humanidad, los sacrificios humanos no tenían lugar en el templo (Nieto, 2001, p. 30).

Como no carecían de una idea aunque imperfecta de la otra vida, cuando alguno moría se sepultaba con su macana.... Por un uso bizarro de este pueblo, el joven que hubiese sido escogido para el sacrificio, se rescataba a sí y a toda su generación y amigos, presentando un tigre muerto (Nieto, 2001, p. 31).

La industria fabril no les era absolutamente desconocida.... En sus canoas, aunque mal construidas por carecer de herramientas al propósito, recorrían no solo la bahía, sino una gran parte de la costa norte y sur (Nieto, 2001, p. 32).

"No era desconocido entre los Calamareños el arte de la medicina, que ejercían por medio de sustancias vegetales y minerales" (Nieto, 2001, p. 38). 
El conocimiento espiritual de los calamareños es falso "Mohanes, Capahies, o adivinos espirituales, cuyas imposturas gozaban de un gran poder en el ánimo del pueblo" (Nieto, 2001, p. 30).

[A los Jadcadhies] "el pueblo les atribuía la virtud de las maravillas y el espíritu profético, cuya opinión alimentaban ellos por medio de mil ceremonias e imposturas" (Nieto, 2001, p. 31).

"Estos personajes se llamaban Mohanes o Adivinos que equivalían a los que en la ignorancia del antiguo mundo de denominaban nigromántico" (Nieto, 2001. p. 38).

"Estos impostores usaban por distintivo en sus gorros, plumas verdes de papagayo (ave entre los indios reputada de inteligencia), y un báculo, de que se servían para marcar en la tierra los signos cabalísticos de sus pretendidas adivinaciones, con que engañaban a sus supersticiosos conciudadanos" (Nieto, 2001, p. 39).

\section{Primera y segunda parte}

Tienen como función narrativa exponer las relaciones de las dos culturas de manera personificada, es decir, a través de acontecimientos puntuales que les suceden a los protagonistas. El deletreo de esta parte indica que:

\section{- El pueblo calamareño es sometido}

Cuando se narran los acontecimientos han transcurrido 33 años de conquista, muchos pueblos indígenas han sido exterminados y sometidos a la esclavitud para servir en las nacientes haciendas de islas del Caribe. En el tiempo del relato existe temor y respeto entre las dos partes en conflicto. Esto se evidencia en que en la cédula real conferida a Pedro de Heredia la conquista del territorio se obligue a dar buen trato a los naturales. Lo cual en realidad explica la razón del solapado altruismo de "buen civilizador" que de los Heredia se esboza en la novela:
La gloria que en mi concepto nos cabe como conquistadores consiste en habernos tocado la dicha de hacer un bien al género humano sacando a los conquistados de la ignorancia y la idolatría para cultivar su entendimiento, y atraerlos al seno de la verdadera religión; y no, en clase de verdugos, sujetar enormes masas de hombres a la humillante condición de esclavos, contraviniendo a las leyes de la creación y la humanidad (Nieto, 2001, p. 81).

En esta situación, el sometimiento del pueblo calamareño se produce por la mediación de sus semejantes, quienes, en función de lenguaraces, convencen a los caciques de las buenas intenciones de los españoles. La novela lo representa así:

El de Carex [el cacique] que hizo resistencia, fue vencido; y los demás, con este escarmiento, se entregaron, rindiendo vasallaje al Rey de España, valiéndose para esto de un Mohán llamado Carón.... Se presentó la India Catalina acompañada de Carón, que iban comisionados por Heredia para proponer la paz, con la condición de reconocer y someterse al Rey (Nieto, 2001, p. 53).

La india Catalina versada ya en estas comisiones, e instruida muy particularmente en esta por Heredia para atraerse a los de Calamar, con el doble objeto de inspirar confianza a los otros y aumentar la colonia con nuevos súbitos, desempeñó su comisión tan diestramente ayudada del crédito de Carón, que los caciques y los indios todos decidieron someterse.... En Capote se establecieron las autoridades españolas, y a los Caciques y sus familias se les conservaron sus títulos y preeminencias, no en la plenitud de su antigua soberanía, sino como una halagüeña distinción de la que podían hacer uso, en todo aquello que no contradijese las leyes del gobierno Español (Nieto, 2001, p. 54).

En estas referencias sobresalen dos cosas: el papel que tuvieron los líderes espirituales, tanto españoles como indígenas, en la búsqueda de la pacificación y el rol de malinche de la India Catalina, similar al de otras en América formadas por los españoles, las cuales actuaron como mediadoras, con un inclinado sesgo hacia la causa española, negando incluso su origen. 
Es de notar cómo el asentamiento de la Colonia en Cartagena somete a los naturales a la religión del conquistador, cumpliendo no una misión mesiánica sino política y económica:

Y de este modo instruidas estas bandadas de catecúmenos de todas edades, eran bautizados sin saber de su nueva religión más que las pequeñas prácticas exteriores de que eran testigos; de que resultaba una mezcla bizarra de cristiandad, pues no abandonando los adultos del todo su antigua religión, confundían la adoración de sus ídolos con la del verdadero Dios, que se les quería hacer conocer (Nieto, 2001, p. 67).

- El pueblo calamareño se revela por la opresión individualizada

El texto plantea, desde el relativismo social, cómo dentro de los mismos colectivos existen consensos y disensiones. Así lo representa la imagen de Catarpa, hijo del Cacique Ostarón, quien se rinde ante el español y que en el transcurso del relato transforma su actitud de rebeldía en sometimiento, pasando por la inconformidad de ver a su pueblo degrado, la sublevación contra el conquistador, debate ideológico con el español Alonso de Heredia, y el sometimiento. Este proceso en la novela se representa de la siguiente manera:

\section{Inconformidad}

¿Qué satisfacción (dijo a su padre) puede resultar al hijo de un Cacique heredero de su soberanía, de unir su suerte a una mujer escogida, que ya no puede participar con su esposo de las delicias del poder supremo, de que le ha despojado la usurpación del extranjero arrojándolos de su patria y hogar? ¿No fue con el objeto de que os sucediésemos, que formasteis el proyecto de unirnos? Y bien: ¿de qué os seremos sucesores ahora? Solo de vanos títulos, que como burla os han dejado para engañar vuestra sencilla credulidad, después que sin la menor resistencia se han humillado todos a los pies del vencedor, sin dar siquiera la más pequeña muestra de recibir el yugo con repugnancia. En hora buena: si vosotros sois indiferentes y soportáis la esclavitud hasta contaros dichos con ella, yo no puedo serlo a la ignominia de mi patria y de mi casa (Nieto, 2001, p. 61).

\section{Sublevación}

Afrenta que se justifica no por el domino del español en general, sino por uno de los conquistadores que agrede al pueblo de Turbaco: "Ellos le impusieron de las buenas disposiciones de sus conciudadanos a la rebelión para sacudir el yugo del detestable Peralta" (Nieto, 2001, p. 91).

\section{Debate ideológico}

Este se da entre Catarpa y Alonso de Heredia, mediante el cual las dos culturas se igualan en razonamientos, para negociar la convivencia con las condiciones del conquistador, claro está:

Si nacimos bárbaros déjanos sin una civilización que provee tantos medios poderosos para subyugar al débil, abandona nuestra tierra, esta tierra que llamáis inculta; nada reclamaron de vosotros mil generaciones que la han ocupado sin quejarse, tranquilos y felices. Nosotros os damos nuestras riquezas, objeto de vuestra insaciable codicia; ningún sacrificio es este para nosotros, pues la libertad no tiene precio (Nieto, 2001, p. 94).

“¿Qué razón ha podido conduciros a lanzaros en una rebelión, cuando yo os dejo vivir en paz?", le preguntó el Adelantado. "El deseo de ser libres [respondió Catarpa], y el de recuperar como príncipe que soy de Calamar, y heredero presunto del señorío de esta tierra, mis derechos usurpados por el extranjero. Si creéis que he hecho mal, decidme vos mismo, jos dejaríais despojar impunemente de estas conquistas que solo os pertenecen por la fuerza? ¿Cederíais vos mismo gustoso al poder de otro usurpador, sin disputarle vuestra posesión? Ahora si no son iguales nuestros derechos a los vuestros para defender nuestras propiedades, jno es mejor dejar de existir que sufrir tal ignominia? Alegáis que nos dejáis en paz, es verdad, pero es una paz deshonrosa, vituperable, comprada al costoso precio de nuestra independencia sostenida por la abyección de la esclavitud (Nieto, 2001, p. 96). 


\section{Sometimiento}

Al fin, pudo la persuasión lo que no había podido la fuerza; y el Castellano ayudado de los ruegos de Ostarón y lágrimas de la esposa del joven indio, logró la promesa de obedecer al gobierno real. Como se aproximaba expedición para el descubrimiento del importante Sinú, Alonso anunció a Catarpa que se preparase para acompañarlo; éste puesto ya en libertad, su gratitud no podía negarse a complacer su protector, y le dio su palabra que era sagrada para Heredia, pues que era la palabra de un valiente (Nieto, 2001, p. 97).

\section{De Ingermina o la hija de Calamar a la hija de Velásquez}

La imagen de Ingermina desde la perspectiva de su origen es bastante opaca. La marca verbal "se tenía", que se refiere en la siguiente cita, es poderosa para la definición de este personaje, quien, como lo veremos más adelante, se transforma: "Se tenía a Ingermina por hija del último Cacique Marcoya, destronado por Ostarón" (Nieto, 2001, p. 58).

Aquí, al decir "se tenía", se está marcando discursivamente la creencia general del grupo al que pertenece Ingermina y se está proyectando la controversia entre el parecer hija de Calamar o ser hija del español Velázquez.

De todos modos, la novela nos presenta una Ingermina que no es igual a las demás mujeres de Calamar, no sólo por su abolengo sino por el retrato de su hermosura, cuyos órdenes de valor son dimensionados desde la cultura occidental, es decir, desde la visión española:

Era Ingermina la joven más bella de su pueblo: su tez casi blanca y sonrosada a que daban realce los rizos de su pelo color azabache, su talle esbelto, sus maneras graciosas, sus facciones proporcionadas, y unos hermosos ojos negros intérpretes de la alegría y demás prendas de su alma, la hacían la reina de los amores, el tormento de más de un joven Calamareño que suspiraba por ella sin esperanza (Nieto, 2001, p. 60).

Notóademás Heredia, la diferencia personal que había entre ella y sus compatriotas: que se acercaba más a la clase Europea que a la Indígena, y que sus gracias y gentileza realzadas en gran manera, podían causar orgullo a la más garbosa hija de la risueña Andalucía (Nieto, 2001, p. 88).

[Alonso de Heredia] "Quedó entonces más satisfecho al descubrir que la joven Calamareña descendía de los soberanos de la tierra. Orgullo propio de casi todo español que siempre quiere ser hijo de algo" (Nieto, 2001, p. 66).

La modelación de la imagen de Ingermina se realiza de manera gradual y planificada, por medio de un proceso de cambio espiritual que la transforma, según los conquistadores, de heredera de unas prácticas falsas a una cristiana verdadera:

[Dice Pedro e Heredia] Urge nuestra salida al Sinú, e Ingermina aún no es cristiana. La expedición no debe durar mucho, pues es preciso de tiempo en tiempo dar descanso a nuestra gente trayéndola a Cartagena. Creo que es la primera vuelta que hagamos todo se podrá realizar. Quiero dejar al Reverendo Padre Fray Clemente Mariana, encargado del resto de su educación y de su instrucción para que reciba el bautismo con todos los conocimientos necesarios al que abraza una nueva fe; y yo me prometo del celo de este varón virtuoso que muy breve nos dará en Ingermina una verdadera cristiana digna esposa de un español (Nieto, 2001, p. 99).

La planificación del relato nos permite ratificar, en la mitad del mismo, cuál es el verdadero origen de Ingermina, presentándola no como indígena pura sino como mestiza: hija de Tálmora, una princesa indígena, y del conquistador Hernán Velásquez, quien habita entre los indios al ser abandonado por sus compañeros españoles. El proceso de transición de hija noble del pueblo Calamar a reconocerse como la hija de Velásquez tiene hondas significaciones tanto de carácter individual como social. En lo individual le permite a Ingermina hacerse igual, no sólo en la fe sino en lo racial, con los españoles dado esencia mestiza. En lo social, este mestizaje tiene repercusiones en el establecimiento de la convivencia pacífica, pues el otro ya es uno, hibridando los sujetos. 
Una vez conocido el verdadero origen de Ingermina, el narrador deja de llamarla de esta manera para darle preeminencia a su carácter de hija de español: "La hija de Velásquez toda desconcertada, entró a aquella casa en que se hospedaba el crimen" (Nieto, 2001, p. 145).

Los consuelos de la religión dados por el Obispo, habían sido tan eficaces para la hija de Velásquez, que procuró transmitirlos a su madre y hermano, particularmente a este último, que aún no era cristiano y quería convertirlo, para desterrarle ciertos ímpetus de desesperación, conducido de los cuales intentaba algunas veces atropellar las guardias y salirse (Nieto, 2001, p. 157).

El castellano fue interrumpido. La hija de Velásquez apartándose repentinamente del grupo, "no temas por mi querido Alonso [dijo], que mis males van a cesar; y tú, monstruo de perversidad [continuó dirigiéndose a Badillo] no te gozarás en tu obra" (Nieto, 2001, p. 175).

Cuando Ingermina deja de ser la hija de Calamar y se configura como hija de Velásquez deja de ser objeto de deseo y ejemplo de sumisión para transformarse en una mujer valiente, que es capaz de defenderse del agresor y de huir saltando del barco donde los llevan presos; es decir, toma el carácter del español, ha dejado de ser indígena para convertirse a la naturaleza de su padre, pues, como él mismo lo indica, "un español nunca deja de serlo":

Este será un motivo que alegaré para separarme de los Juyas, y venir a la Nueva Cartagena a reunirme a mis compatriotas, pues tantas vicisitudes, tantos trabajos y desgracias, no han podido borrar de mi corazón el recuerdo de mi tierra natal; nunca he olvidado que soy hijo de una nación ilustre y magnánima, en fin, que soy Español (Nieto, 2001, p. 121).

\section{El zaqueo y el engaño sigue}

La resolución del conflicto a nivel individual no se extiende a lo colectivo. Al final de la novela, Alonso, Ingermina y su familia, Catarpa y sus indios, viven en una especie de paraíso romántico. Esto no sucede con los demás pueblos indígenas, ya que el proceso de conquista debe seguir, en el caso de los Heredias, la conquista de zaqueo pasa por la tierra del Sinú, por el Urabá y el Cauca:

Don Pedro de Heredia había traído de esta campaña, tesoros más que suficientes para alagar la codicia de los conquistadores y alentarlos a nuevas empresas. Él había despojado los templos de sus adornos e ídolos de oro, y para formar un cálculo aproximado de lo que podía valer el producto de esa expedición, baste decir que el puerco espín de oro, quitado al templo de Zipacua, pesaba cinco arrobas y los ocho patos sagrados del mismo metal tomados al de Mahates cuarenta mil ducados (Nieto, 2001, p. 76).

Sigue la conquista de engaño cambiando el oro por bagatelas: porque estos naturales desconociendo la belleza y adelanto de las artes cualquiera brujería española los alucinaba como una cosa maravillosa que jamás habían visto, y la cambiaban por su oro que reputaban en menor precio (Nieto, 2001, p. 77).

\section{Lo inútil de la empresa}

La empresa de los Heredia termina en fracaso, dado que esta se organizó como un sistema de asociación en la cual los inversionistas tomaban su remuneración del oro saqueado. La belicosidad de los nativos, la avaricia de los españoles y la obligación de entregarle a la corona parte del botín hacen que los recursos en oro fueran insuficientes. Por esta razón, Heredia tiene dificultades con la tropa y después con la Corona. Al final de sus días Pedro de Heredia muere prófugo en un naufragio. El texto presenta indicios de esta condición: "Estuvo a pique de poner la administración en anarquía, lo que dio lugar a un pequeño tumulto, producido por el descontento de la tropa. La llegada del adelantado restableció el orden y la confianza" (Nieto, 2001, p. 105).

En cuanto a Alonso de Ojeda, el prologuista de la novela explica cómo "toda novela que intente ser un tanto realista exige, para su verisimilitud, un telón de fondo histórico. Pero que se sepa, Alonso de Heredia no entró, con las (bellas o no) indígenas de Calamar, en otro comercio erótico que el habitual del amancebamiento" (Nieto, 2001, p. 22). 
Y cierra afirmando: "La verdad fue muy otra. La conquista de Hispanoamérica constituyó, por desdicha, el choque de dos especies sanguinarias, una de las cuales, sin embargo, contaba con la superioridad de las armas de fuego" (Nieto, 2001, p. 21).

\section{Referencias}

Avelar, I. (s.f.). Ingermina, de Juan José Nieto: antagonismo y alegoría en los orígenes de la novela caribeña. Recuperado en mayo de 2001 de http://res.uniandes.edu.co/view.php/680/ index. . php?id $=680$.

Calderón, D. (2010). Construcción de la imagen en los Parientes de Ester de Luis Fayad. Heterodoxias. Tunja: Universidad Pedagógica y Tecnológica de Colombia. Escuela de Idiomas, Cátedra Rafael Gutiérrez Girardot.

Català, J. (2005). Fenomenología de la imagen compleja. Barcelona: Universidad Autónoma de Barcelona.

Debray, R. (1998). Vida y muerte de la imagen: historia de la mirada en Occidente. Barcelona: Paidós.

Ducrot, O. (1988). Polifonía y argumentación. Cali: Universidad del Valle.

Ducrot, O. (1999). El decir y lo dicho. Barcelona: Paidós.

Durand, G. (2006). Estructuras antropológicas del imaginario. México: Fondo de Cultura Económica. Geertz, C. (1989). El impacto del concepto de cultura en el concepto del hombre. En C. Geertz. La interpretación de las culturas. Barcelona: Gedisa.

Nieto, J. (2001). Ingermina o la hija de Calamar. Medellín: Fondo Editorial Universidad Eafit. Raymond, W. (s.f.). En: Novela y poder en Colombia. Recuperado en mayo de 2011 de http:// www.javeriana.edu.co/narrativa_colombiana/contenido/bibliograf/williams/ideologia.htm. Consultado 05/2011

Vivero, M. (2001). El texto, teoría y análisis lingüístico. Madrid: Arrecife. 